\title{
Research on the Influence of International Commodity Market on China Stock Market
}

\author{
-From the Perspective of Financing Liquidity
}

\author{
Li Sicong \\ School of economics, Shanghai University \\ Shanghai, P. R. China \\ kierenhenson@hotmail.com
}

\begin{abstract}
This paper studies the interaction mechanism between commodity market and China stock market from the perspective of financing liquidity. Since the financialization of commodities, the correlation between commodities and the stock market has experienced its first rise after experiencing the sharp fluctuations in the rise and fall. This paper constructs a series of liquidity indexes which can explain $17 \%$ correlation change between the stock market and commodity market. The empirical study reaches a conclusion that the degree of correlation between the two markets will increase significantly when funding liquidity deteriorates. This study shows that the change of the financing liquidity condition of overall financial markets is an important factor affecting the interactivity of commodity market and stock market. In addition to providing a new perspective for discussing the interactivity of commodity and stock market, this paper also has important reference value for the practice of asset allocation.
\end{abstract}

Keywords-Commodity Market; Stock Market; Financing Liquidity; Market Linkage

\section{INTRODUCTION}

In traditional concept, commodity attribute is the basic attribute of commodities, which plays a role in determining the price of commodities. In commodity markets, the real economy's demand for commodities and supply determines the price of commodities. But with the deepening of the financialization of commodity markets, the financial attributes of commodities have also been strengthened, particularly commodities that have been included in the international commodity price index. Commodity financialization means that financial institutions in the commodities market plays an increasingly important position, in the operation of the behavior of the commodity market is more affected by the financial market behavior, thus weakening the commodity value of commodities, making it the another type of investment or speculative tradable financial instruments, or derivative financial instruments.

After joining the World Trade Organization, China's economic development has had a close correlation with foreign economy. With the continuous improvement of the financial markets, the Chinese stock market gradually plays an important role of economic barometer. As opening up, China has a growing demand for commodities. From the point of the real economy, the price fluctuation of commodities can also affect the operating conditions of commodity producers and downstream companies, thus affecting the fluctuation of stock prices.

Liquidity is the core of all markets (Amihud, 1988) [1] and the lack of liquidity, whether commodities or stocks, will have a huge impact on both commodities and stocks. Therefore, the commodity market can also be treated as a financial market, directly linked to the stock market. From the perspective of liquidity, this paper studies the influence of commodity market and stock market.

\section{LITERATURE REVIEW}

\section{A. Financialization of Commodity Markets}

Gorton \& Rouwenhorst (2006) [2] argue that 2000 is the cut-off commodity financialization. Before 2000, commodity markets had low degree of correlation between stocks, bonds and other financial markets, which means commodity market was a relatively independent market. Studies of Erb \& Harbey (2006) [3], Stoll \& Whaley (2009) [4] say commodities should be brought into the investment portfolio, it can effectively reduce the risk of a portfolio. Thus, investment institutions widely hold commodity positions, and caused the influx of a large number of funds. The sharp rise in commodity prices and violent volatility are seen as two of the manifestations of the financialization of commodities (Cui Ming, 2012) [5]. Hamilton (2009) [6] tried to explain the sharp rise and volatility of the commodity prices with the economic cycle and the real economic fundamentals, but Buyuksahin \& Robe (2014) [7] studied in the relationship between stock index commodity futures index, found that the correlation between the two indexes rise sharply after 2008, and was positively correlated with hedge fund speculation.

\section{B. Definition of Liquidity}

In recent years, liquidity has caught more and more attention of scholars. The concept of liquidity was first proposed by Keynes's "general theory of employment, interest and money" which put forward the liquidity preference theory, It is a theory that people has a psychological preference in order to meet the demand of payment may to store money, and timely invest in the market to gain higher yields. The concept of early liquidity is limited to the asset of money, but with the deepening of liquidity research, liquidity is not limited to an asset. 
Levine (1997) [8] further expanded the concept of liquidity into the convenience of economic agents converting assets into purchasing power at acceptable prices. But it was just the definition of market liquidity, circulation of funds wasn't taken into account. Brunnermeier et al. (2009) [9] argues that liquidity should include market liquidity and financing liquidity. Market liquidity is the degree of difficulty for the holders of assets to sell assets, while the financing liquidity is the difficulty of obtaining funds from the financial market.

Their study further broadened the explanatory power of liquidity for different markets and different asset characteristics, they point out that finance is not a one-way relationship between liquidity and liquidity, but a two-way relation. Tighter market fund leads to the deterioration of the financing liquidity, thereby reducing liquidity.

Along with the decline of asset liquidity, the risk of financing transaction increases, which will further aggravate the financing liquidity. At a particular time, this mechanism would strengthen the relationship between the two, creating a liquidity spiral that would have an impact on all assets held by investors. In this way, even in the basic perspective, two unrelated assets will have the synchronization of price fluctuations due to liquidity.

\section{DATA AND RESEARCH DESIGN}

\section{A. Data of the Rate of Return}

This empirical study adopted in February 2010 - March 2018 trading the S\&P Goldman Sachs Commodity total return Index (SPGSCI) and the Shanghai and Shenzhen 300 index (HSI300) as the index of the international commodity futures market and China stock market index, and calculate the logarithm yield. All data sources are Wind information.

Table 1 reports the descriptive statistics of commodity futures and stock index daily returns. From February 2010 to March 2018, the daily average yield of commodity index is $0.024 \%$, the highest daily profit is $5.481 \%$, and the maximum daily loss is $-6.743 \%$. The average daily yield of the stock market is $0.010 \%$, higher than the yield of commodity index, the highest daily rate of return is $6.499 \%$, and the maximum daily loss is $-9.154 \%$. The static correlation coefficient of commodity index and stock index is 0.14 .

TABLE I. DESCRIPTIVE STATISTICS OF RETURN ON ASSETS

\begin{tabular}{|c|c|c|c|c|c|c|}
\hline & \multicolumn{6}{|c|}{ Descriptive Statistics } \\
\cline { 2 - 7 } & Obs. & Mean & Median & Std.Dev & Skewness & Kurtosis \\
\hline SPGSCI & 1978 & -0.024 & 0.000 & 1.222 & -0.143 & 5.578 \\
\hline HSI300 & 1978 & 0.010 & 0.037 & 1.493 & -0.767 & 8.201 \\
\hline
\end{tabular}

\section{B. Liquidity Index}

Reference to previous research, this article selects the threemonth interbank market interest rate (SHIBOR) Shanghai and three-month Treasury rates China (TB-SHIBOR), the difference between the 10-year corporate debt rating to $\mathrm{AA}^{-}$ with the difference between the 10-year Treasury rates China (LBAA), monthly average yield of brokerages share (Broker), the monthly average yield of banks share (Bank). TB-SHIBOR is the monthly average value of the daily difference between the rate of interest rate spreads between the Shanghai interbank offered rate and the short-term Chinese government bond which represents credit spread. A rise in credit spreads means higher funding costs for markets (Campbell \& Taksler, 2003) [10]. LBAA is the monthly average of the daily change in the credit spread between the $\mathrm{AA}^{-}$grade corporate bond and the 10-year Chinese government bond. The rise of AA- grade credit spreads means higher borrowing costs and credit risk (Longstaff, 2015; Jiang Xianfeng, 2017) [11-12]. TB-SHIBOR and LBAA will change in reverse to liquidity which means higher index of these two indexes could reflex worse liquidity. BROKER is the monthly rate of return of the Top 30 listed Brokerage in China. BANK is monthly rate of return of the Top 20 listed Bank in China (Boyson, 2010) [13]. The brokerages and banks will increase the margin requirement, due to operating pressure, in order to lower the risks which could reduce the financing liquidity in the market. BROKER and BANK will change in line with liquidity. Namely, higher liquidity could be observed by higher BROKER and BANK.

Table 2 reports the descriptive statistics of liquidity indexes.

TABLE II. DESCRIPTIVE STATISTICS OF LIQUIDITY INDEXES

\begin{tabular}{|c|c|c|c|c|c|c|}
\hline & \multicolumn{5}{|c|}{ Descriptive Statistics } \\
\cline { 2 - 6 } & Obs. & Mean & Median & Std.Dev & Skewness & 0.679 \\
\hline TB-SHIBOR & 97 & 1.306 & 1.189 & 0.620 & -0.275 \\
\hline LBAA & 97 & 3.734 & 3.853 & 0.555 & 1.415 \\
\hline BROKER & 97 & 0.799 & -0.975 & 13.018 & 7.821 \\
\hline BANK & 97 & 0.945 & 0.701 & 7.744 & 0.685 \\
\hline
\end{tabular}


TABLE III. CORRELATION COEFFICIENT OF LIQUIDITY INDEXES

\begin{tabular}{|c|c|c|c|c|}
\hline & \multicolumn{3}{|c|}{ Pearson correlation coefficient } \\
\cline { 2 - 5 } & TB-SHIBOR & LBAA & BROKER & \multicolumn{1}{c|}{ BANK } \\
\hline TB-SHIBOR & 1.000 & 0.217 & -0.042 & 0.004 \\
\hline LBAA & 0.217 & 1.000 & 0.799 & 0.788 \\
\hline BROKER & -0.042 & 0.799 & 1.000 & 1.000 \\
\hline BANK & -0.004 & 0.148 & 0.788 & 0 \\
\hline
\end{tabular}

Table 3 reports the Pearson correlation coefficient of liquidity indexes.

The results of correlation analysis show that there is a positive correlation between TB-SHIBOR and LBAA, but it is negatively correlated with the Broker and Bank, and is consistent with the previous expectation. However, four liquidity indexes measure different aspects of the liquidity, and no single indicator can fully reflect the impact of financing liquidity on market linkage. Therefore, the principal component analysis is carried out to select a comprehensive index to measure the liquidity condition. The results of principal component analysis show that the principal component with the eigenvalue greater than one is the first principal component. The proportion that the first principal component can explain is $46.17 \%$. For the convenience and reliability of the model, this paper selects the first principal component as the comprehensive index of the change of liquidity. The larger the principal component, the worse the liquidity; Conversely, the smaller the primary component, the better the liquidity.

\section{Correlation of Rate of Return on Assets}

This article selects the past 263 trading days rolling correlation coefficients which is on the basis of the logarithm yield of the index of the SPGSCI and HSI300. The formula is as follows:

RCorrelation $_{t}$

$=\frac{1}{n} \sum_{i=1}^{n} \frac{\sum S P G S C I \times H S I 300-\frac{\sum S P G S C I \times \sum H S I 300}{N}}{\sqrt{\left(\sum\left(S P G S C I^{2}\right)-\frac{\left(\sum S P G S C I\right)^{2}}{N}\right)\left(\sum\left(H S I 300^{2}\right)-\frac{\left(\sum H S I 300\right)^{2}}{N}\right)}}$

RCorrelation $_{\mathrm{t}}$ is the monthly average correlation between logarithmic yields of S\&P Goldman Sachs Commodity total return Index and the HSI300 index over the past 263 trading days, where $n$ represents there're $n$ trading days in month $t$. And $N$ is assumed to be 263 .

This article selects the differences of monthly average correlation coefficients between month $t$ and month $t-1$ to measure the-up-and-down of commodity futures index correlation with the stock market index. DRCorr ${ }_{t}$ is designed to describe the change on correlation of commodity and stock market. The formula is as follows:

DRCorr $_{\mathrm{t}}=$ RCorrelation $_{\mathrm{t}}-$ RCorrelation $_{\mathrm{t}-1}$
D. Overall Market Conditions and Correlation of Rate of Return on Assets

In order to verify the hypothesis that liquidity spiral, especially when the overall market conditions are bad, correlation of yield between commodity market and the stock market will increase, the correlation between the two should be increased, thus the following measurement model was constructed:

DRCorr $_{\mathrm{t}}=\beta_{0}+\beta_{1} \times \mathrm{SPGSCI}_{\mathrm{t}}+\beta_{2} \times \mathrm{HSI}_{300_{\mathrm{t}}}$

$+\lambda_{1} \times$ ComdiStress $_{\mathrm{t}}+\lambda_{2} \times$ StkStress $_{\mathrm{t}}+\mu_{\mathrm{t}}$

Where ComdiStress $t= \begin{cases}S P G S C I_{t}, & \text { if } S P G S C I_{t}<\overline{S P G S C I} \\ 0, & \text { if } S P G S C I_{t} \geq \overline{S P G S C I}\end{cases}$

$$
\text { StkStress }_{\mathrm{t}}= \begin{cases}H S I 300_{t}, \text { if } H S I 300_{t}<\overline{\mathrm{HSI300}} \\ 0, & \text { if } \mathrm{HSI300}_{t} \geq \overline{\mathrm{HSI300}}\end{cases}
$$

ComdiStress $\mathrm{t}_{\mathrm{t}}$ represents slump index of commodity markets, and StkStress $s_{t}$ represents slump index of stock markets. If the assumption of liquidity spiral is met, the $\beta_{0}$ and $\beta_{1}$ should be significantly negative.

\section{E. Financing Liquidity and Correlation of Rate of Return on Assets}

In order to verify whether the financing liquidity has a significant explanatory power on the correlation of rate of return on assets when the financing liquidity deteriorates. Therefore, the following empirical test model is designed:

$$
\text { DRCorr }_{t}=\alpha_{0}+\alpha_{1} \times \text { Financing }_{t}+\varepsilon_{t}
$$

Where the data of Financing $g_{t}$ is the first principal component adopted before. The larger the Financing index, the more difficult the Financing is, the worse the Financing liquidity is. According to previous expectations, $\alpha_{1}$ should be significantly positive. 


\section{RESULTS}

A. Overall Market Conditions and Correlation of Rate of Return on Assets

The regression results of the model are as follows:

$$
\begin{aligned}
\text { DRCorr }_{\mathrm{t}} & =-0.019^{* * * *}+0.158^{*} \times \text { SPGSCI }_{\mathrm{t}}+0.278^{* * *} \mathrm{HSI300}_{\mathrm{t}} \\
& -0.367^{* * *} \times \text { ComdiStress }_{\mathrm{t}}-0.675^{* * *} \times \text { StkStress }_{\mathrm{t}}
\end{aligned}
$$

Where $\beta_{0}, \beta_{1}, \beta_{2}, \lambda_{1}, \lambda_{2}$ corresponding $t$ value respectively $4.22,1.95,2.74,-3.18,-3.75$. And $*$, **, *** respectively represent the levels of significance at $10 \%, 5 \%$ and $1 \%$ respectively. The adjusted R-square is 0.08 and the $\mathrm{F}$ value is $6.71^{* * *}$, indicating that the model has a certain explanatory power to the correlation between the asset returns of the two markets.

The regression results show that the slump indexes are inversely correlated with the difference of the correlation between the commodity market and the stock market. That is, when the either market is in bad condition, every $1 \%$ decrease in the commodity market leads to a $0.367 \%$ increase in the correlation coefficient between the stock market and the stock market. For every $1 \%$ reduction in the stock market, the correlation coefficient will rise by $0.675 \%$. There is a significant inverse relationship between the overall market condition and the correlation between asset returns. Specifically, the impact of the overall market situation is mainly manifested in that when the market yield is poor, the correlation between commodities and the stock market will increase significantly.

\section{B. Financing Liquidity and Correlation of Rate of Return on} Assets

The regression results of the model are as follows:

$$
\text { DRCorr }_{\mathrm{t}}=0.001+0.011^{* * * *} \times \text { Financing }_{\mathrm{t}}
$$

Among them, the $t$ values corresponding to $\alpha_{0}$ and $\alpha_{1}$ are 0.89 and 6.72 respectively. The adjusted $\mathrm{R}$-square is 0.17 , and the $\mathrm{F}$ value is 35.52 , indicating that the overall model's explanatory ability is still acceptable.

The results show that the adjusted R-square indicates that the change in financing liquidity conditions can explain the correlation between the $17 \%$ commodity market and the stock market yield. Specifically, the correlation between commodity and stock market yields will rise by $0.011 \%$ when each $1 \%$ rise in the liquidity index.

\section{CONCLUSIONS AND SUGGESTIONS}

From the perspective of financing liquidity, this paper reveals the intrinsic interaction mechanism between commodities market and stock market. Specifically, when an external financial market deterioration, a tighter financing, financial institutions will usually increase the risk to control the cost of financing, high financing costs will lead to deterioration of the liquidity of the assets, making it prices fall further, and liquidity spiral chain reaction, etc. Liquidity pressure across the market investors have to reduce its holdings of commodities market positions, the prices of the commodities market, and the correlation of the external financial market. When the financial condition is stable, there is sufficient investment fund, with the high level of financing liquidity and market liquidity. Investors are required with less margins, for brokerages and banks thinking the risk of mortgage is manageable and not hitting a financing limit. Thus, the financing market is not sensitive to the change of the cost of financing. In economic crisis and credit crisis, cross-market traders have to sell their positions held in commodity markets to lower their risks and supplement their liquidity in other financial market for the market panic in the stock market sell-off caused the value of stocks falling sharply. And investors bought will decline, the market liquidity suddenly drops. At the same time, the financial sectors by increasing margin ratio to make up for the loss suffered by crisis, hit a limit on the investors' capital that Banks are reluctant to lend to investors stop investors by buying the stocks to provide liquidity to the market, the shortage of financing to make trade further reduce, deterioration of market liquidity into another stage, finally forms the lower funding liquidity and lower liquidity in the market.

Thus, in normal times the central bank has the capacity and obligation to reduce the cost of liquidation and maintain the stable operation of the financial system. Once systematical liquidity crisis occurs, the central bank should inject liquidity into the system, to prevent a vicious cycle of financing liquidity and assets liquidity in the market, suspended as a result of a vicious cycle of destructive impact on the system. In the same time, strict monitoring measures should be taken to effectively reduce the information asymmetry and moral hazard. Poor expectations may cause liquidity risk for local commercial banks. So regulators should strengthen the information exchanges of the depositors to avoid public panic and bankrupts. We should also broaden the channels of financing between financial institutions and deepen and improve China's capital market. We should standardize the mechanism of the trading operation of various financial products, increase the source of institutional financing, reduce the financing cost, and keep the financing liquidity of various institutions and the market liquidity in virtuous circle.

The research of this paper also has important practical significance for the construction of asset portfolio. In building portfolios, the correlation between assets must be taken into account in order to diversify investment risk. In this paper, research has found that the commodity is not in the market liquidity condition, disperse investment risks effectively, even due to the rise of asset correlation can lead to the original portfolio risks have risen sharply, portfolio losses may be rising sharply. This was particularly true during the financial crisis of 
2008. Therefore, the impact of liquidity shock on the correlation between commodities and stock market should be fully considered in future asset portfolio allocation.

\section{REFERENCES}

[1] Amihud Y, Mendelson H. 1988, "Liquidity, Volatility, and Exchange Automation" [J]. Journal of Accounting, Auditing, and Finance, 3(4): $369 \sim 395$

[2] Gorton, Gary, and K. Geert Rouwenhorst. 2006. "Facts and Fantasies about Commodity Futures" [J], Financial Analysts Journal, 62(2): 47 68.

[3] Erb, C. and C. Harvey. 2006, "The Strategic and Tactical Value of Commodity Futures" [J]. Financial Analysts Journal, March/April, 69 97.

[4] Stoll, H.R., and R.E. Whaley, 2009. "Commodity Index Investing and Commodity Futures Prices.” Working Paper, Owen Graduate School of Management, Vanderbilt University,

[5] Cui Ming. 2012, "Motivation, controversy and enlightenment of commodity finance" [J]. Modern Management Science, (12):87-89. (In Chinese)

[6] Hamilton, James D. 2009. "Causes and Consequences of the Oil Shock of 2007 - 08". No.w15002.National Bureau of Economic Research,

[7] Büyüksa, Bahattin, and Michel A. Robe.2014, "Speculators, Commodities and Cross-Market Linkages" [J], Journal of International Money and Finance, 42(1): $38 \sim 70$.

[8] R. Levine. 1997, "Financial Development and Economic Growth: Views and Agenda" [J]. Journal of Economic Literature, 35(2): 688 726.

[9] Brunermeier M K, Pedersen L H. "Market Liquidity and Funding Liquidity" [J]. Review of Financial Studies, 2008, 22(6): $2201 \sim 2238$.

[10] Campbell, John Y, and Glen B.Taksler.2003. "Equity Volatility and Corporate Bond Yields" [J], Journal of Finance, 58(6): $2321 \sim 2350$.

[11] Longstaff, 2015, Francis A., Sanjay Mithal, and Eric Neis. 2005. "Corporate Yield Spreads: Default Risk or Liquidity? New Evidence from the Credit Default Swap Market" [J], Journal of Finance, 60(5): $2213 \sim 2253$.

[12] Jiang Xianfeng, 2017, "The difference in credit rating of Chinese and foreign enterprises and their determinants", Working Paper, No.2017-5. People's Bank of China. (In Chinese)

[13] Boyson, Nicole M., Christof W. Stahel, and Rene M.Stulz.2010. "Hedge Fund Contagion and Liquidity Shocks" [J]. Journal of Finance, 65 (5): $1789 \sim 1816$ 